\title{
Investigations on the heat transfer within intake and exhaust valves at various engine speeds
}

\author{
Mahfoudh Cerdoun $^{\mathrm{a}, *}$, Smail Khalfallah ${ }^{\mathrm{a}}$, Ahmed Beniaiche ${ }^{\mathrm{a}}$, Carlo Carcasci ${ }^{\mathrm{b}}$ \\ a Laboratory of Turbomachinery/Ecole Militaire Polytechnique, BP17 Bordj-el-Bahri, 16046 Algiers, Algeria \\ ${ }^{\mathrm{b}}$ Department of Industrial Engineering/University of Florence, Via Santa Marta, 3 -Florence, Italy
}

\section{A R T I C L E I N F O}

\section{Article history:}

Received 23 August 2019

Received in revised form 24 October 2019

Accepted 5 November 2019

Available online 14 November 2019

\section{Keywords:}

Exhaust/intake valves

Heat transfer

Engine speed

Temperature map

\begin{abstract}
A B S T R A C T
The heat transfers within the intake valve differs than the exhaust valves, due to the difference in the boundary condition surrounding each valve. This paper concerns a comparison of the heat transfer coefficient (HTC) at various engine speed and the temperature distribution through exhaust valves and intake valves. The boundary condition are assessed using basic concept of heat transfer and correlation related to internal cbustin engine. To assess perfectly the real effect of the valves surrounding, an adequate subdivision of the valve is used where the heat transfer coefficient and the adiabatic wall temperature (AWT) for each subdivision are evaluated during one engine cycle. An average value of these two parameters is calculated and introduced as a boundary condition in a FEM model. This procedure is repeated for diverse engine speeds, and therefore, the trend of the real boundary condition in term of HTC and AWT are given versus engine speed. The comparison in term of HTCs shows different behaviour of valves surrounding mainly in the seat and stem zones. The obtained model is used to highlight the temperature map of an exhaust valve and intake valves for the different operating condition in addition to zones of fort thermal gradient and thus, areas of maximum thermal load can be specified, which help automobile manufactures to avoid valves failures.
\end{abstract}

(c) 2019 Elsevier Ltd. All rights reserved.

\section{Introduction}

Exhaust and intake valves are located in the cylinder head and their main function is to allow fresh air or gases to enter/leave the engine cylinder [1]. Because of the valves role and the exigencies of the recent new vehicles, considerable efforts are focusing on the aim of allowing valves to realize the requirements demanded. The prediction of the temperature map of such components plays primordial role in the design process and allows engineers to produce a more robust engine and the earlier, the distribution of the temperature within valves is known, the higher chance to reach robust design. The design of valves is directly related to the boundary condition, which may complicate the conception process. Thus, quantitative and qualitative information on heat transfer through valves at diverse boundary condition (different engines and loads) permit the optimal design at large operating condition, moreover, extrapolation to the extreme conditions will be possible and with accurate precision. Also, It is decisive to get the temperature map within both the exhaust and intake valve to detect extreme

\footnotetext{
* Corresponding author.

E-mail address: cerdoun.mahfoudh@gmail.com (M. Cerdoun).
}

temperature regions and then check if the valve material's temperature limits are respected or not.

In recent times, with the environment restriction and simultaneously, the increased of specific output (engine downsizing and turbocharging) progressive arduous conditions surround both the exhaust and the intake valve.

Even if the study of the heat transfer within intake valves has an important role to perform the ICE efficiency, since any increase in their temperature will directly transformed to the incoming fluid to the cylinder, rare works were focused on them, whereas researchers are mostly interesting to heat transfer in the intake manifolds. Also, in the open literature, there is little information how the boundary condition enclosing the valves varies with the engine speed.

Accordingly, the main contributions of the present work can be cited in below:

1- Perform the numerical approach presented by the authors by considering the relative motion of the valves and flow transition inside the exhaust/intake manifolds and over the seat region.

2- Determine the trend of the heat transfer coefficients and adiabatic wall temperature of each zone at divers engine speed 


\section{Notations}

\begin{tabular}{|c|c|c|c|}
\hline$A$ & area $\left(\mathrm{m}^{2}\right)$ & $V_{p}$ & mean piston speed $(\mathrm{m} / \mathrm{s})$ \\
\hline$B$ & bore diameter $(\mathrm{m})$ & $V_{s}$ & swept volume $\left(\mathrm{m}^{3}\right)$ \\
\hline$c_{2}$ & vickers micro-hardness correlation confident $[-]$ & & \\
\hline$C_{d}$ & discharge coefficient & $\alpha$ & coefficient of thermal expansion $\left[\mathrm{K}^{-1}\right]$, Flow angle (deg) \\
\hline$D_{h}$ & hydraulic diameter $(\mathrm{m})$ & $\beta$ & seat angle (deg) \\
\hline$D_{m}$ & mean valve diameter $(\mathrm{m})$ & $\sigma$ & RMS surface roughness (m) \\
\hline E & Young' s modulus, MPa & $v$ & poisson's ratio \\
\hline$F$ & force $(\mathrm{N})$ & $\mu$ & dynamic viscosity $(\mathrm{kg} / \mathrm{m} \mathrm{s})$ \\
\hline G & gap thickness (m) & $\varepsilon$ & constant \\
\hline$H_{c}$ & micro-hardness (MPa) & & Comstant \\
\hline$k$ & thermal conductivity $(\mathrm{W} / \mathrm{m} \mathrm{K})$ & \multicolumn{2}{|c|}{ Subscripts } \\
\hline$L$ & length (m) & $r$ & reference state \\
\hline$L_{v}$ & valve lift (m) & 0 & stagnation condition \\
\hline $\operatorname{Pr}$ & Prandtl number & & pressure unstream the restriction \\
\hline$p_{m}$ & motoring pressure $(\mathrm{Pa})$ & & pressure upstream the restriction \\
\hline$R$ & radial distance $(\mathrm{m})$, resistance, $\mathrm{K} / \mathrm{W}$, gas constant & \multirow{2}{*}{\multicolumn{2}{|c|}{ Abbreviation }} \\
\hline $\operatorname{Re}$ & Reynolds number & & \\
\hline$T$ & Temperature $(\mathrm{K})$ & TCC & thermal contact conductance \\
\hline$u$ & differential expansion $(\mathrm{m})$ & HTC & heat transfer coefficient $\left(\mathrm{W} / \mathrm{m}^{2} \mathrm{~K}\right)$ \\
\hline$V, v$ & Volume $\left(\mathrm{m}^{3}\right)$, velocity $(\mathrm{m} / \mathrm{s})$ & & \\
\hline
\end{tabular}

3- Compares the temperature map and the maximum temperature of the intake valves to the exhaust valves after real regime of an ICE.

The remainder of this paper gives consecutively a brief review of previous works on the heat transfer within valves, a description of the numerical approach adopted in the present and result of an application considering both valves.

\section{Literature survey}

The identification of the parameters which influence the heat transfer through exhaust valve have been the aim of first researches [2,3], and still constitute the attention of the research community since exhaust valve overlap of several field such as heat transfer, metallurgy. The first attempts of the valve studding started by identifying the different parameters influencing the heat transfer through valves. Gibson et al. [2] measured the operating temperatures of valves showing that they depend mainly on fuel air ratio, engine cooling and spark timing, the range of the temperature it between $600^{\circ}$ and $750^{\circ} \mathrm{C}$, for the case of preignition, the temperature might exceed $800^{\circ} \mathrm{C}$. Zipkin and Sanders [3] extended the parameters that influence the valve temperature. They developed a semi empirical equation to correlate the valve temperature including engine-operating condition. Pandey et al. [4] noted that cyclic loading at high temperatures causes valves fail, a decrease of hardness and a corrosion of exhaust valves.

The details of the flow through the exhaust/intake port-valvecylinder are widely studied in the last century [5-7], generally, the flow is characterized by the discharge coefficient; ratio of isentropic area and geometric area. In unsteady measurement, Han et al. [6] covered a pressure ratio range from 1.9 to 5.4 using special test rig unsteady flow, Woods et al. [7] carried out a program of unsteady flow test covering a pressure ratio of five for the exhaust valve and two for intake valve with the aim to determine the boundary conditions. The valve was tested with and without pipes, the boundary conditions have been found to be independent of the length pipe and the effective area of the exhaust valve based upon the constant pressure model is independent of pressure ratio above a value of 2. Recently, Franzke et al. [8] presented new approach to model the wall heat transfer in the exhaust port and manifold, in which the subdivision of the exhaust process is based on the blow-down and a push-out phase, and the exhaust system is divided into several sections. In experimental study, Plotnikov et al. [9] focused on gas-dynamic unsteadiness effects on heat transfer in the intake and exhaust systems of an ICE. The finding shows that unsteadiness reduces the instantaneous local heat transfer intensity about 1.3-2.5 times.

The main parameter to determine in the exhaust/intake system of ICE when studying the heat transfer of such pulsatile fully developed turbulent flow is the heat transfer coefficient [10], which is based mainly on the similitude theory [11].

According to Mavropoulos et al. [12] and Mavropoulos [13], the phenomena related to unsteady internal combustion engine heat transfer could be divided in two main modes: cyclic engine heat transfer phenomena and long-term response heat transfer phenomena related to non-periodic variations of engine speed and load, resulting from the large time scale.

In the recent years, several studies were focused on the exhaust valves mainly in the determination of the temperature map. In his technical note, Tomlinson et al. [14] developed a method to evaluate the maximum value of exhaust valve temperatures, based upon the concept of fourth-root temperature. 
Shojaefard et al. [15] used a finite-element method to model the transient thermal analysis of an exhaust valve via Ansys APDL. The model includes exhaust valve, seat, guide and spring. Karamangil et al. [16] investigated numerically the effect of different carbon film thickness on the exhaust valve where the stress distributions and temperature profiles on exhaust valve are obtained depending on different carbon film thickness and operation conditions. The obtained results showed the increase of the carbon film thickness decreases the temperature differences on the valve and the carbon film at the valve head creates additional thermal resistance. Witek [17] used a numerical model to study the failure and thermomechanical stress of the exhaust valve of ICE.

In the aim to determine a feasible robust design solution and to predict the effect of engine design and operating condition changes, Baniasad et al. [18] presented a developed a new methodology to predict the cycle average valve temperatures in a 6-Sigma context by considering a wide range of engine factors. The methodology assesses the main effects of on the exhaust valve temperature and engine performance and creates the transfer functions by considering all the factors and their interactions.

For a limited engine speed range (5000-5250 rpm), Roth [19] focused on the determination of both temperature map stress/ strain in the exhaust valve. The geometry included exhaust valve, port section, guide, seat method, and used the FEM method for the resolution. The boundary condition are provided from a steady state CFD simulation of flow over the valve at different valve lifts.

Cerdoun et al. [20] presented a numerical approach to assess the temperature map of an exhaust valve, based mainly on the basic concept of heat transfer and available correlations. The authors split the geometry of the valves into seven zones in the aim was to isolate the effect of each part of the cylinder head. Therefore, the average values of the HTC and adiabatic wall temperature were taken as boundary conditions during one engine cycle in the FEM model. In their second paper, Cerdoun et al. [21] performed the previous model by introducing the effect of lubricating oil and the contact resistance between guide and engine block. They included also the differential displacement of both the guide and engine block. They concluded that, the boundary conditions implemented as an average of HTC and adiabatic wall temperature, underestimate the temperature, whereas cyclic boundary condition required more run time to reach steady state.

Recently, Alpaya et al. [22] a transient thermal model for the exhaust valve of a four-stroke, in which the valve is subdivided in zones, the boundary condition are obtained for each subdivision and the transient heat transfer coefficient and temperature boundary conditions are applied using the commercial code FloEFD.

\section{Numerical approach and procedure}

\subsection{Methodology}

To well carry out this investigation, there is a need for an appropriate subdivision considering the different parameters affecting the heat transfer through the valve. Such subdivision may help to better identify and quantify the boundary conditions. The same subdivision of the exhaust valve as Cerdoun et al. [20,21] is adopted for the intake valves, since it considers the real boundary condition and considers the complex surrounding geometry of engine block. According to Fig. 1, seven zones are considered as follows:

a) Combustion face: it may be treated as part of chamber combustion.

b) Seat: The main heat is being dissipated when exhaust valves are closed.

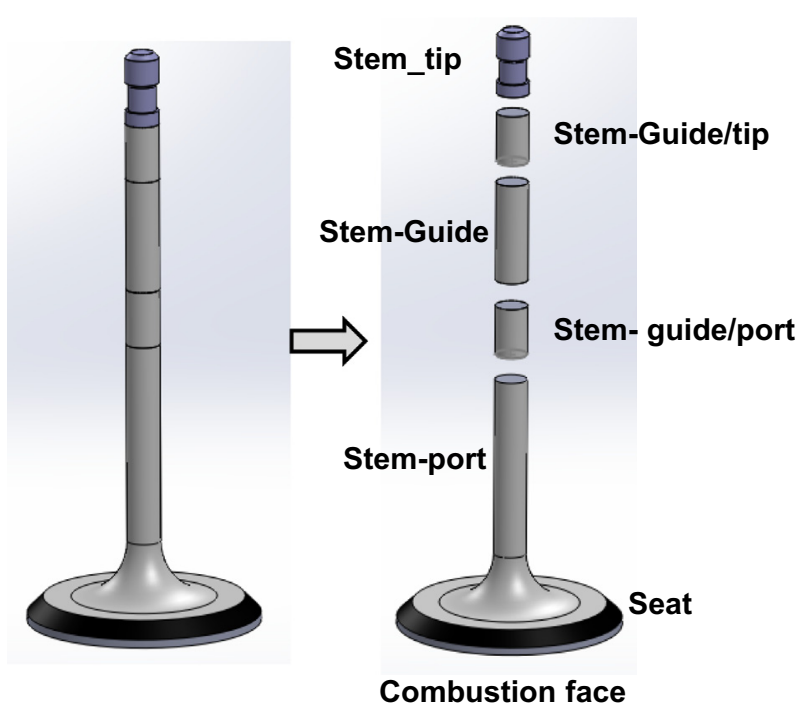

Fig. 1. Valve's zones.

c) Stem-port: This part of valve stem is located in the exhaust manifold during all the engine cycle,

d) Stem-guide: Part of stem witch mate with the guide, it is exposed to the heat transfer cooling.

e) Stem-tip: End of valve located in train-cam system.

f) Stem port/guide: This part is located in intermediate between the two zones stem-port and stem-guide.

g) Stem_ guide/tip: As the previous zone, this part is located in intermediate between the stem guide and the stem tip.

The heat transfer coefficient in the ICE is based mainly on the assumption that the heat transfer rate can be taken proportional to the difference of temperature between the fluid and the engine block. This assumption of the heat transfer process is still being applied in numerous studies [15-19], even if it has not rigorous theoretical or experimental point of view (Annan [23]).

In the present study, the unsteady HTC and adiabatic wall temperature $T_{a}$ for each zone of exhaust valves versus engine crank angle is calculated and then the time-averaged values for a fourstroke engine of HTC and $T_{a}$ are estimated as follow:

$\stackrel{-}{H T C}=\frac{1}{4 \pi} \int_{0}^{4 \pi} H T C d \theta \bar{T}_{a}=\frac{1}{4 \pi H T C} \int_{0}^{4 \pi} T_{a} \cdot H T C d \theta$

\subsection{Methods to estimate the instantaneous heat transfer coefficient}

\subsubsection{Heat transfer coefficient in valve combustion face}

The heat transfer in the cylinder of ICE is mainly done by convection as stated by Heywood [1]; it is a non-uniform and unsteady and presents high fluctuations in time and in space during one engine cycle [8-13]. A famous correlation widely used to estimate instantaneous spatially-averaged coefficient heat fluxes is that of Woschni [24], relating between Nusselt and Reynolds number by $N u=a R e^{m} \operatorname{Pr}^{n}$. So, By emphasizing that the exponent $\mathrm{m}$ is equal to 0.8 ,thermal conductivity kand dynamic gas viscosity $\mu$ are proportional to $T^{0.75}$ and $T^{0.62}$, respectively, Woschni [24], presented the heat transfer by

$H_{T C} C_{\text {Combustionface }}=a P^{0.8} T^{-0.55} B^{-0.2}\left[C_{1} V_{p}+C_{2} \frac{V_{s} T_{r}}{p_{r} V_{r}}\left(p-p_{m}\right)\right]^{0.8}$ 
The term between parentheses, represent the effective gas velocity. $\mathrm{P}$ and $\mathrm{T}$ are the instantaneous pressure and temperature, respectively. The bore diameter $B$ is the characteristic length and $V_{p}$ is mean velocity of piston. $T_{r}, P_{r}$ and $V_{r}$ are temperature, pressure, and volume, respectively, evaluated, as at any reference state, such as inlet valve closing or combustion start. $\mathrm{P}$ and $\mathrm{p}_{\mathrm{m}}$ are the firing and the motoring pressure, respectively at the same crank angle. Values suggested for $\mathrm{C} 1$ and $\mathrm{C} 2$ are given in Table 1

Since both intake and exhaust valves are included in the combustion chamber of the ICE, the Woschni [24] correlation may be used in both valves to estimate the HTC.

\subsubsection{HTC valve seat}

The heat transfer within this zone can be treated into two phases according to the close of open of the valve. In the first one, the heat transfer is done mainly by convection, whereas the second one is modeled by conduction mode.

3.2.2.1. HTC valve-seat: Valve open. The transient mass flow rate across an intake or an exhaust valve is expressed by the following equation [1]:

$\dot{m}=\frac{C_{d} A_{r} P_{0}}{\left(R T_{0}\right)^{\frac{1}{2}}}\left(\frac{p_{T}}{p_{0}}\right)^{1 / \gamma}\left\{\frac{2 \gamma}{\gamma-1}\left[1-\left(\frac{p_{T}}{p_{0}}\right)^{(\gamma-1) / \gamma}\right]\right\}^{1 / 2}$

In cases where the pressure ratio exceeds the critical value, the mass flow is given by

$\dot{m}=\frac{C_{d} A_{r} P_{0}}{\left(R T_{0}\right)^{\frac{1}{2}}} \gamma^{1 / 2}\left(\frac{2}{\gamma+1}\right)^{(\gamma+1) /[2(\gamma-1)]}$

For the case of exhaust valves, $P_{0}$ and $T_{0}$ are the stagnation pressure and temperature, which are taken as the pressure and temperature in the cylinder and $p_{T}$ is the pressure upstream the restriction. In the case of an intake valves, $P_{0}$ and $T_{0}$ are the stagnation condition upstream the seat whereas $p_{T}$ is the pressure inside the cylinder. $C_{d}$ is the discharge coefficient representing the ratio between isentropic area and geometric area. The geometric mini$\operatorname{mum} A_{\min }$ flow area between valve and seat was used as the reference area $\left(A_{r}\right)$.

Thus, the Reynolds number in the case of no chock wave is given as

$R e=\frac{C_{d} D_{h} P_{0}}{\mu\left(R T_{0}\right)^{\frac{1}{2}}}\left(\frac{p_{T}}{p_{0}}\right)^{\frac{1}{\gamma}}\left\{\frac{2 \gamma}{\gamma-1}\left[1-\left(\frac{p_{T}}{p_{0}}\right)^{\frac{\gamma-1}{\gamma}}\right]\right\}^{\frac{1}{2}}$

According to Kastner et al. [25], there are three separate stages to the flow area development as valve lift increases.

${ }^{6}$ Low valve lifts, the minimum flow area corresponds to a frustum of a right circular cone.

${ }^{6}$ Medium valve lifts, the minimum is no longer perpendicular to the valve seat.

${ }^{6}$ Fully opened valve, the minimum flow area is the annular space formed between the port and the valve stem.

The relations used to identify the lift range and minimum section summarized in [20,21].

Table 1

Woschni's coefficient.

\begin{tabular}{ll} 
Gas exchange period & $C_{1}=6.18, C_{2}=0$ \\
Compression & $C_{1}=2.28, C_{2}=0$ \\
Combustion and expansion & $C_{1}=2.28, C_{2}=3.2410^{-3}$ \\
\hline
\end{tabular}

For the first and second stage of valve lift, the classic correlation of Dittus-Boelter [25] for the convection heat transfer for turbulent flow in pipe is used.

However, for the third case, the heat transfer can be assumed to an internal cylinder heat transfer or to an external flow [20,21]. Assuming a turbulent flow, the Churchill and Bernstein [26] correlation can be used for external flow.

3.2.2.2. HTC valve-seat: Valve close. To adequately assessing the heat transfer conducted from valves to seat, the real model of the contact valve seat is transformed to a theoretical model. This theoretical model considers that the heat flux follows a form of a truncated cone from the valve until cooling fluid. (Fig. 2) [20,21].

Thus, write as the equivalent global resistance including the conduction resistance with:

$R_{\text {tot }}=R_{\text {tc_valve_seat }}+\frac{L_{\text {seat }}}{k_{\text {seat }} A_{\text {seat }}}+R_{\text {tc_seat_Al }}+\frac{L_{A l}}{k_{A l} A_{A l}}+\frac{1}{h_{H_{2} O} A_{H_{2} O}}$

where $\mathrm{k}_{\text {seat }}, \mathrm{k}_{\mathrm{Al}}$ and $\mathrm{h}_{\mathrm{H}_{2} \mathrm{O}}$ are the thermal transfer coefficient.

Once the material resistance is defined, the equivalent thermal resistance requires the estimation of the thermal contact conductance (TCC) valve seat and seat_aluminuim. Many researchers have conducted studies on TCC for several decades with both theoretical and experimental methods. The classical models are Mikic [27] elastic model, Cooper, Mikic and Yovanovich (CMY [27]) plastic model and elastoplastic model proposed by Sridar and Yovanovich [28]. Fig. 3 illustrates a schematic seat-valve contact showing asperities, and graphical representations of the absolute surface slope $\mathrm{m}$ and the RMS surface roughness.

A dimensionless relationship between applied pressure, material properties and thermal contact conductance was established by Cooper, Mikic and Yovanovich [27], the proposed model was

$h_{c}=1.45 \frac{k_{s} m_{s}}{\sigma_{s}}\left(\frac{P}{H_{c}}\right)^{0.985}$

where $H_{c} i$ sthe microhardnes.P is the specific pressure.

Song and Yovanovich [28] developed a formula expressing of the relative pressure $P / H_{c}$.as

$\frac{P}{H_{c}}=\left[\frac{P}{1.62 c_{1}\left(\frac{\sigma_{s}}{\sigma_{0}} m\right)^{c_{2}}}\right]^{1 /\left(1+0.071 c_{2}\right)}$

where $\sigma_{0}=1 \mu \mathrm{m}, c_{1}$ is the Vickers correlation coefficient and $c_{2}$ is Vickers size index.

Sridhar and Yovanovich [29] suggested empirical relations to estimate Vickers micro hardness coefficients, using the bulk hardness of the material. To calculate the specific pressure $P$, the Newton's first law is applied to the system: Valve, seat, cam system $[20,21]$.

Both exhaust and intake valves can be treated using the aforementioned methods, the only parameters that change are the thermodynamic properties and the geometrical characteristic of the valves.

\subsubsection{HTC valve stem_porte}

To calculate the heat transfer across cylinder and since its main direction is inclined from the stem axial about an angle imposed by the exhaust and the intake pipe shape, the model of Carcasci et al. $[30,31]$ is adopted. The heat transfer can be modeled as the sum of heat transfer across a cylinder and heat transfer parallel to a flat plat since these latter are widely studied [25,26] (Fig. 4).

$h_{\text {stem_port }}=\varepsilon_{\text {stem_port }} \cdot h_{\text {cylinder }}+\left(1-\varepsilon_{\text {stem_port }}\right) h_{\text {flatpalt }}$

A weighting coefficient $\left(\varepsilon_{\text {stem_port }} \in[0,1]\right)$ can be used to favor configuration against the other. 


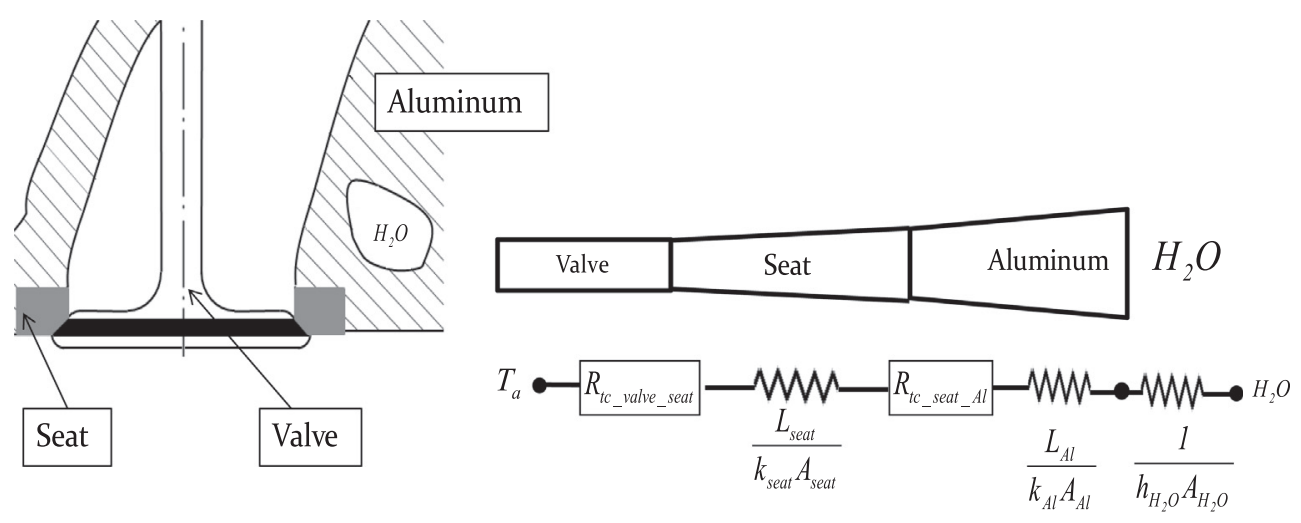

Fig. 2. Transformed of the real model to theoretical model.

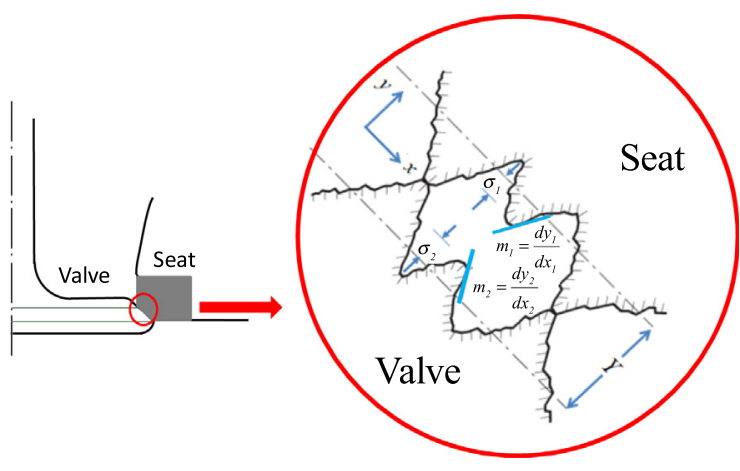

Fig. 3. Illustration of Seat-valve contact.
It has to note, that for the case of an intake valves, the flow properties, the inlet air direction and the relative motion should be adjusted in order to bascule from the exhaust valves configuration to intake valve configuration.

For the considered flat plat, the velocity is the sum of the axial gas velocity and the valve velocity.

Table 2 summarize the formulations used in the present paper to evaluate the Nusselt number basing on the Churchill and Bernstein [26] correlation. The Nusselt number is calculated regarding the Reynolds number range. The velocity of the flow is calulctaed by incorporating the relative motion of the valves.

3.2.4. HTC stem guide. The heat transfer in the zone stem_guide can be assumed to a typical conduction through multilayer cylinder (Fig. 5). However, the transition from real model to theoretical one incorporates the effect of lubricating oil and the contact resis-

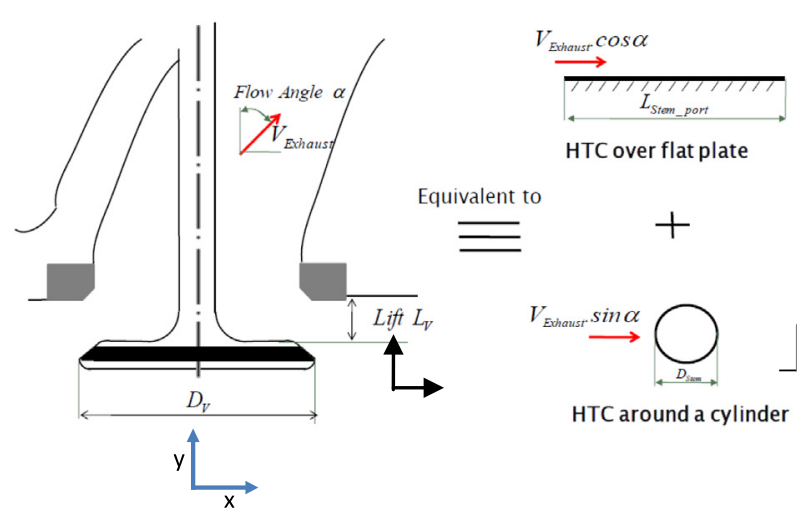

a)

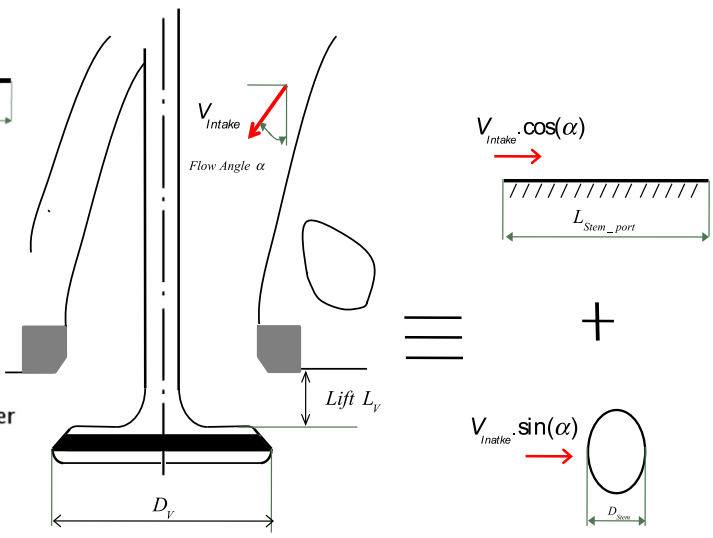

b)

Fig. 4. Transformation of the real model to the theoretical model for the case of (a) exhaust valve (b) intake valves.

Table 2

Nusselt number formulation for the stem_port zone.

\begin{tabular}{lll}
\hline & Flat plat & Cylinder \\
\hline Flow speed & $V_{y}=V_{\text {exhaust } / \text { intake }} \cos (\alpha)+V_{\text {valve }}$ & $V_{x}=V_{\text {exhaust } / \text { intake }} \sin (\alpha)$ \\
Reynolds number & $\operatorname{Re}_{L}=\frac{\rho_{\text {gaz }} V_{y} L_{\text {stem }}}{\mu_{\text {gaz }}}$ & $\operatorname{Re}_{D}=\frac{\rho_{\text {gaz }} V_{x} D_{\text {stem }}}{\mu_{\text {gaz }}}$ \\
Nusselt number & $\left\{\begin{array}{c}\operatorname{Re}_{D} \in[1-4000] \\
\operatorname{Re}_{D} \in[4000-40000] \\
\operatorname{Re}_{D} \in[40000-400000]\end{array}\right] \begin{array}{c}N u_{D}=0.43+0.53 \operatorname{Pr}^{0.31} \operatorname{Re}_{D_{D}}{ }^{0.5} \\
N u_{D}=0.43+0.193 \operatorname{Pr}^{0.31} \operatorname{Re}_{D}{ }^{0.618} \\
N u_{D}=0.43+0.0265 \operatorname{Pr}^{0.31} \operatorname{Re}_{D}{ }^{0.805}\end{array}$ \\
\hline
\end{tabular}




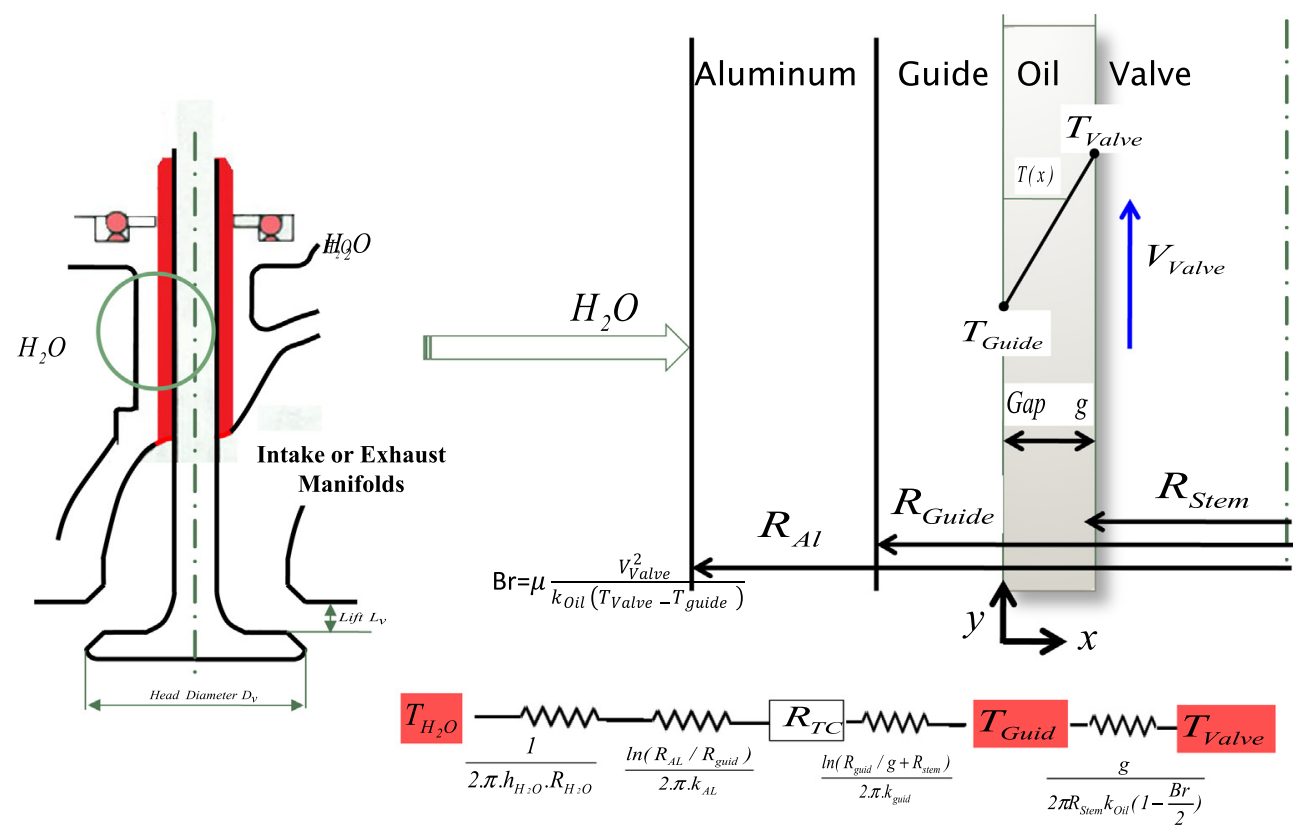

Fig. 5. Illustration of heat transfer process in the stem_guide zone.

Table 3

Some geometrical of the test engine.

\begin{tabular}{ll}
\hline Characteristics & Values \\
\hline Number of cylinders & 2 \\
Cylinder volume $\left(\mathrm{cm}^{3}\right)$ & 610 \\
Fuel & $\mathrm{C}_{7.3} \mathrm{H}_{13.9}$ \\
Compression ratio & 11.48 \\
Cylinder bore $(\mathrm{mm})$ & 84 \\
Stroke $(\mathrm{mm})$ & 55 \\
Connecting rod length $(\mathrm{mm})$ & 124 \\
Number of intake valves & 2 \\
Number of exhaust valves & 1 \\
Engine speed (rpm) & $3200-7500$ \\
Mean exhaust valve diameter $(\mathrm{mm})$ & 32 \\
Mean intake valve diameter $(\mathrm{mm})$ & 38 \\
\hline
\end{tabular}
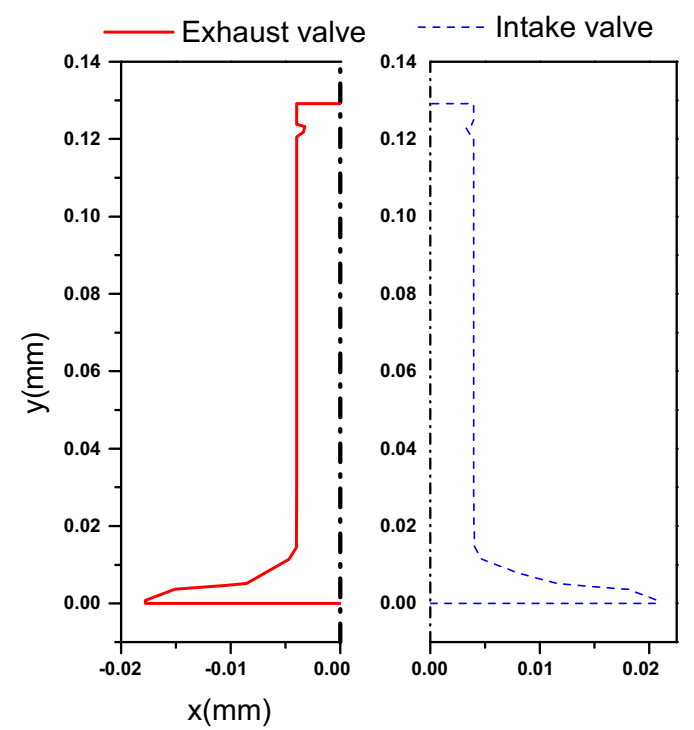

tance between the guide and the engine block. The global resistance may be expressed by:

$R_{e q}=\frac{1}{2 \pi R_{A l} h_{\mathrm{H}_{2} \mathrm{O}}}+\frac{\ln \left(\frac{R_{A l}}{R_{\text {Guide }}}\right)}{2 \pi k_{A l}}+R_{t c \_ \text {Al_guide }}+\frac{\ln \left(\frac{R_{\text {Guide }}}{g+R_{\text {Stem }}}\right)}{2 \pi k_{\text {Guide }}}+R_{\text {Oil }}$

where $g$ is the thickness of the oil film.

The thermal conductivity coefficient and geometry of engine block and guide allowed identifying the thermal resistance.

The gap spacing is assumed to be very small compared to the stem radii and guide radii so that curvature effects may be ignored. The lubricant fluid can be considered as Couette flow between two parallel plane walls. One of the walls (valve) is moving in its own plane with the constant velocity $V_{\text {Valve }}$. The other wall (guide) is assumed to be at rest. The valve motion drives the fluid filling

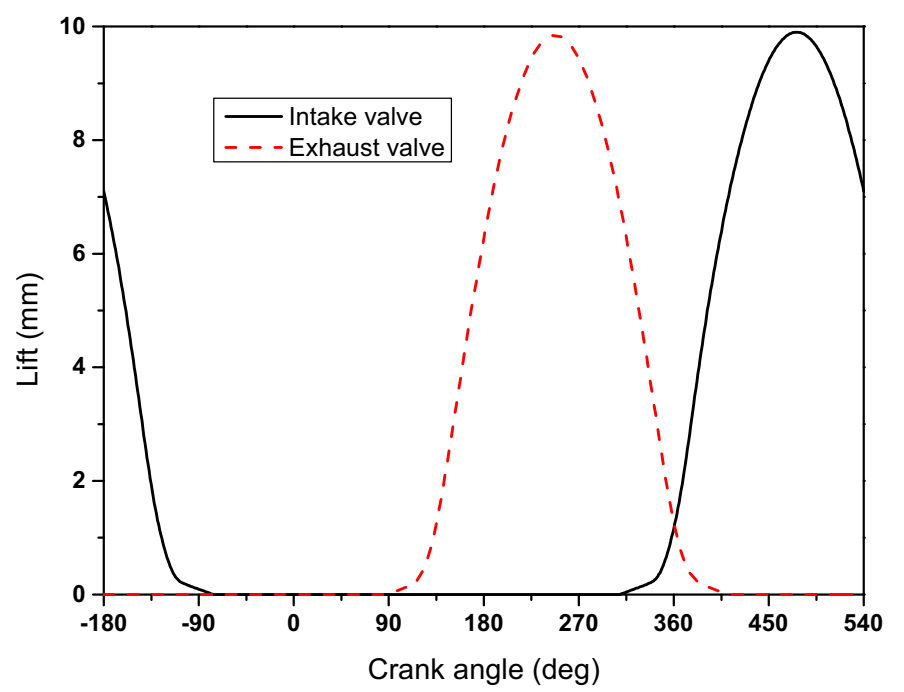

Fig. 6. Exhaust and intake valves geometry (a) dimension, (b) lift. 


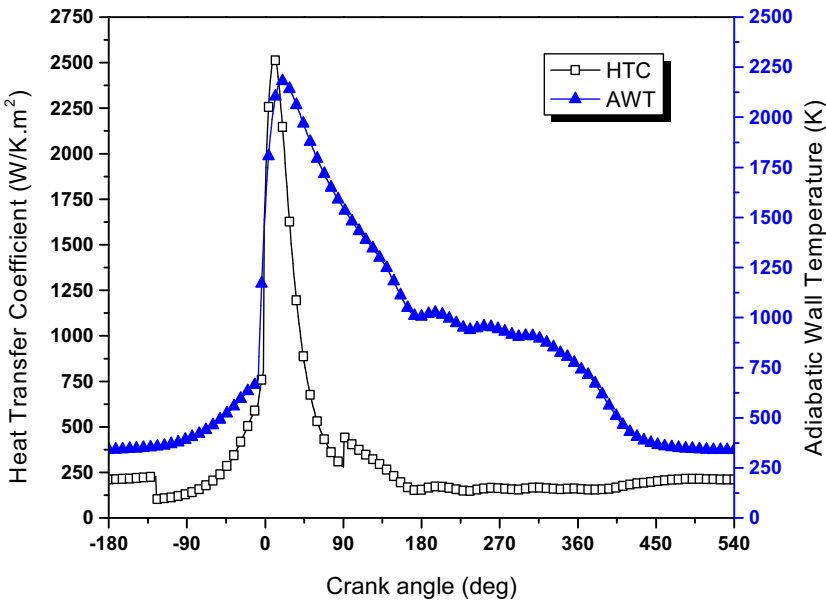

a) HTC and AWT at Combustion face

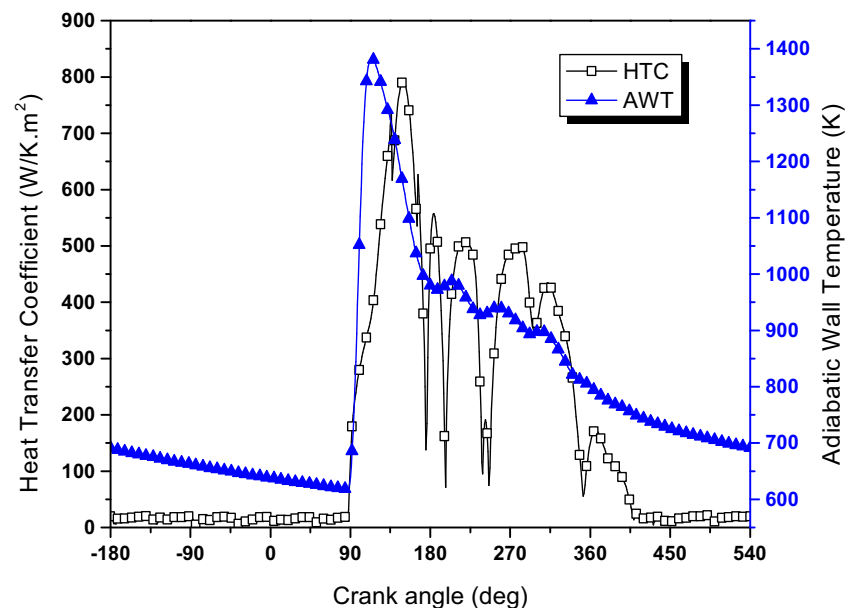

c) HTC and AWT at stem-port

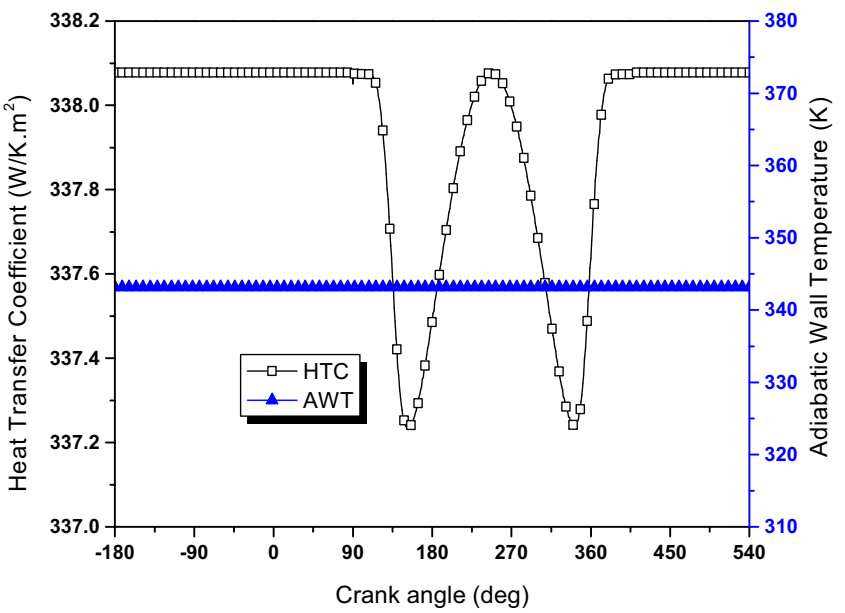

e) HTC and AWT at stem- guide

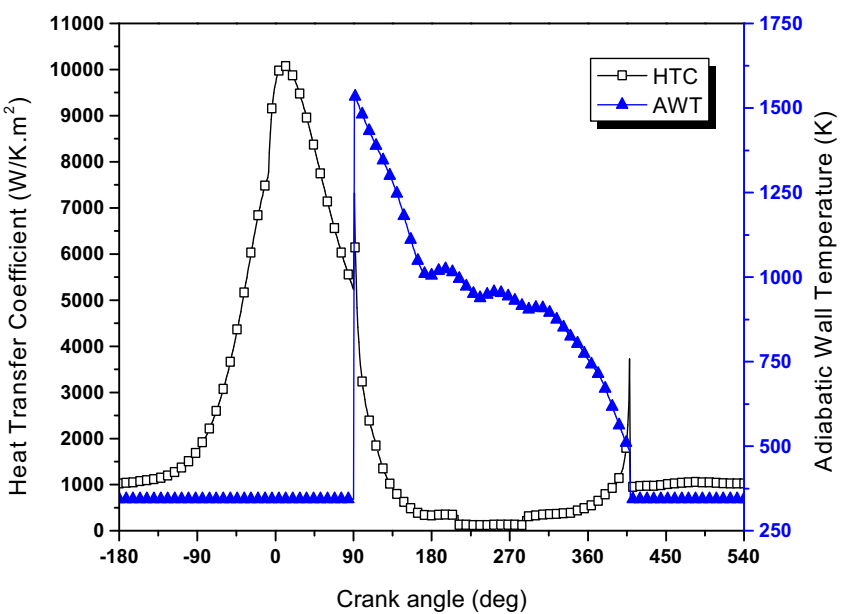

b) HTC and AWT at the seat

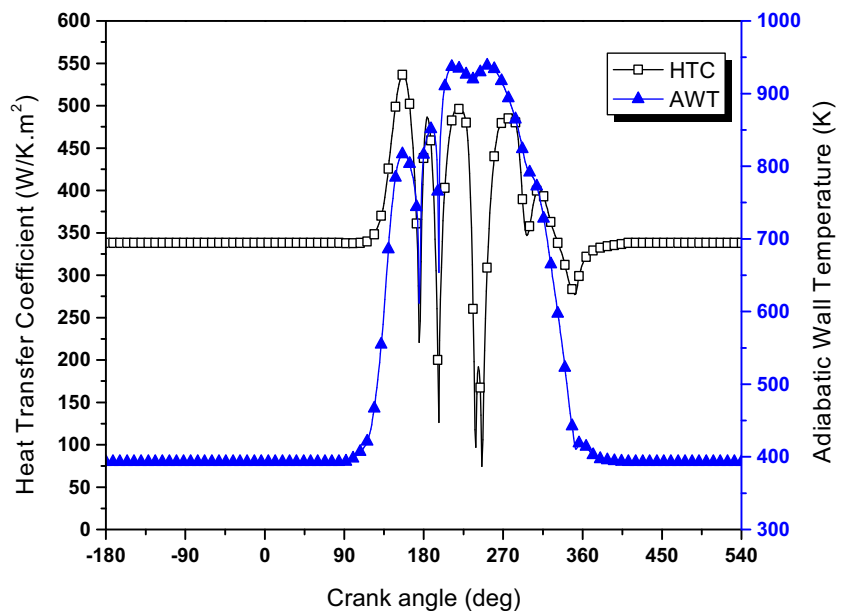

d) HTC and AWT at stem-port/guide

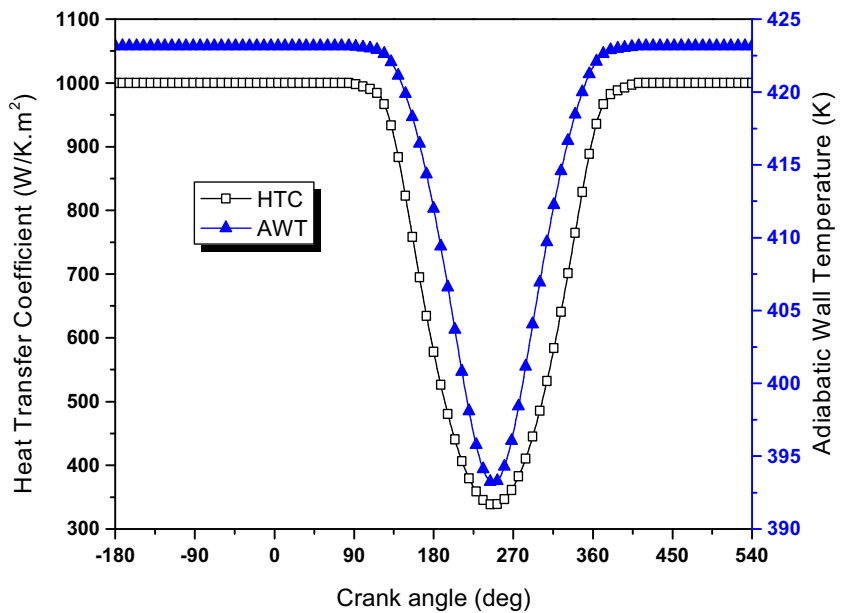

f) HTC and AWT at stem- guide/cam

Fig. 7. The evolution of transient HTC and AWT at engine speed of $5500 \mathrm{rpm}$.

the gap of spacing between the two walls. The wall temperatures are assumed uniform and are denoted $T_{\text {valve }}, T_{\text {guide }}$ for the valve and guide, respectively. The fluid properties assumed to be constant. With the assumption of parallel flow, radial velocity component is negligible.
The determination of the thermal resistance of the oil film $\boldsymbol{R}_{\boldsymbol{O} \text { il }}$ is well explained in Cerdoun et al. [20,21], whereas the determination of the contact thermal resistance $\boldsymbol{R}_{t c \_ \text {guide_Al }}$.

In the cylindrical joint between guide and the block engine depends on interference existing at the time of operation. A model 


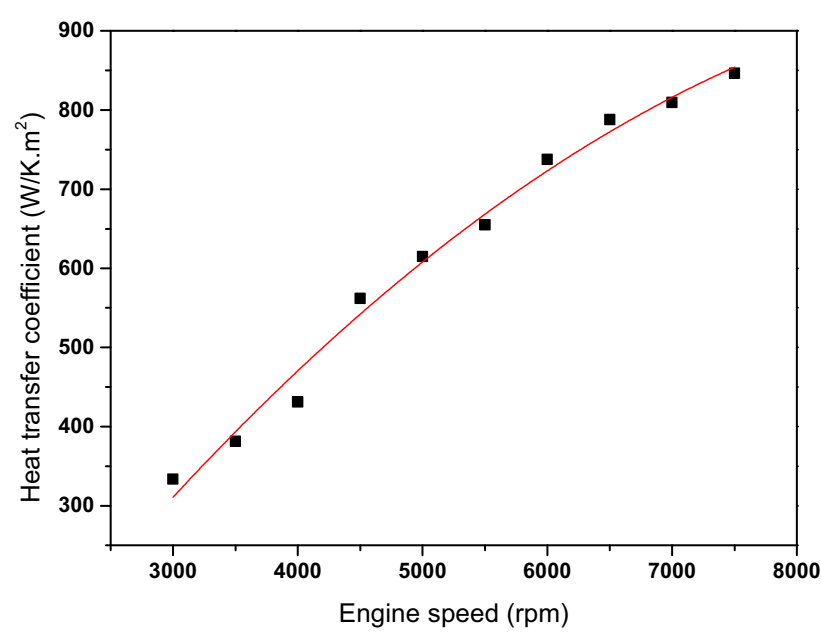

(a)

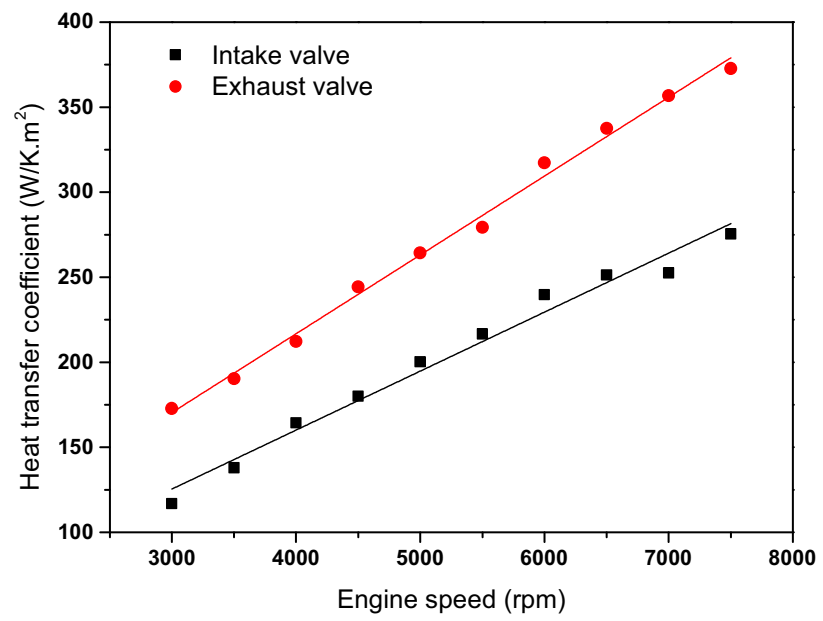

(c)

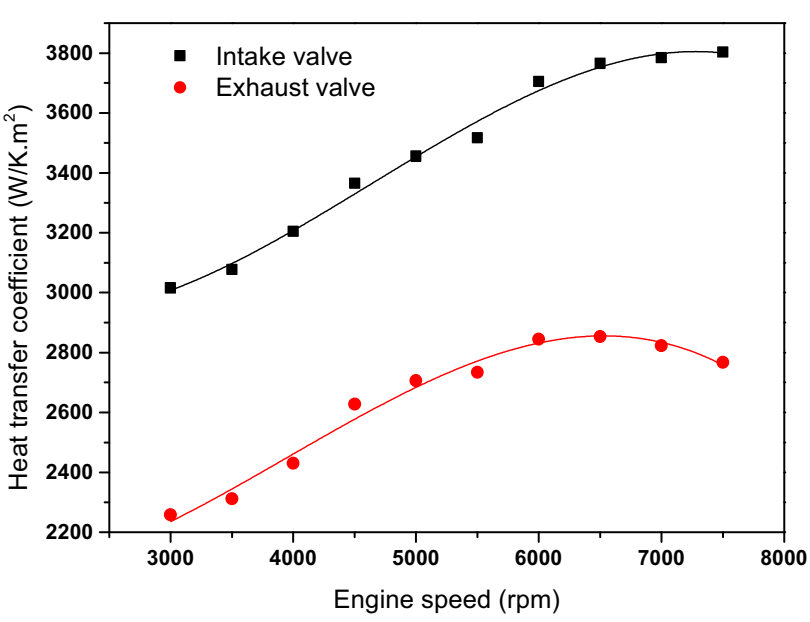

(b)

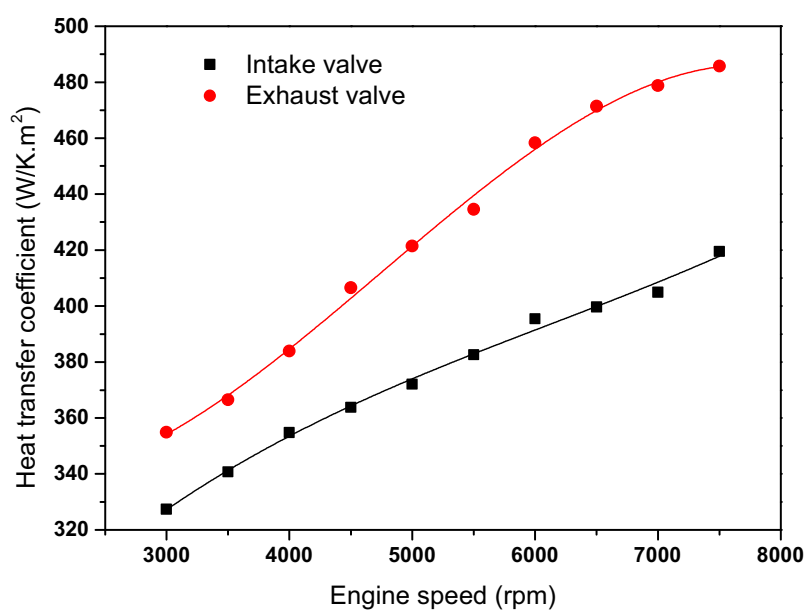

(d)

Fig. 8. Averaged heat transfer coefficient versus engine speed for (a) combustion face (b) seat (c) stem_port and (d) stem_port/guide zone.

Table 4

Coefficient of the polynomial fitting.

\begin{tabular}{|c|c|c|c|c|c|}
\hline \multicolumn{6}{|c|}{ Polynomial $Y=A+B * X+C * X^{\wedge} 2+D^{*} X^{\wedge} 3$} \\
\hline Zones & & A & B & $\mathrm{C}$ & $\mathrm{D}$ \\
\hline Combustion face & & -301.704 & 0.23762 & $-1.11310^{-5}$ & 0 \\
\hline \multirow[t]{2}{*}{ Seat } & Intake & 3407.5 & -0.5269 & $1.6710^{-4}$ & $-1.1910^{-8}$ \\
\hline & Exhaust & 2249.7 & -0.3197 & $1.4010^{-4}$ & $-1.18510^{-8}$ \\
\hline \multirow[t]{2}{*}{ Stem_port } & Intake & 21.42 & 0.034 & 0 & 0 \\
\hline & Exhaust & 31.36 & 0.046 & 0 & 0 \\
\hline \multirow[t]{2}{*}{ Stem_guid/port } & Intake & 186.5 & 0.06784 & $-8.3410^{-6}$ & $5.5410^{-10}$ \\
\hline & Exhaust & 384.62 & -0.05741 & $1.1910^{-5}$ & $1.4010^{-9}$ \\
\hline
\end{tabular}

developed by Chakravarti and Madhusudana [32,33] is adapted to the present study by Cerdoun et al. [21] is reutilized.

3.2.5. HTC valve stem_guide/port. In order to obtain the heat transfer coefficient in this zone, the result of the stem_guide and stem_port are used. The length of this zone is equal to the maximum of the exhaust valve lift. When the valve is close, the treatment of this zone is similar to the stem_guide zone and when the valve is fully open, this zone is treated as stem_port zone. In the remained case, the heat transfer is an average value between the heat transfer coefficient of the stem_guide and stem_port depending on the part of stem including in the guide. These three cases can be written as following.

$$
\begin{aligned}
H T C_{\text {stem_guide/port }}= & \left(\frac{L_{v, \operatorname{Max}}-L_{v}}{L_{v, \text { Max }}}\right) H T C_{\text {stem_guide }} \\
& +\left(\frac{L_{v}}{L_{v, \text { Max }}}\right) H T C_{\text {stem_port }}
\end{aligned}
$$




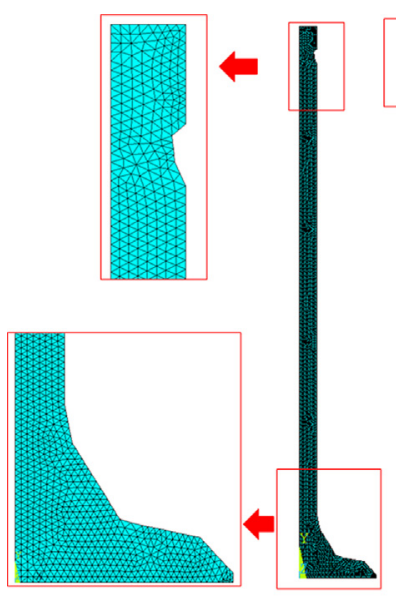

a)

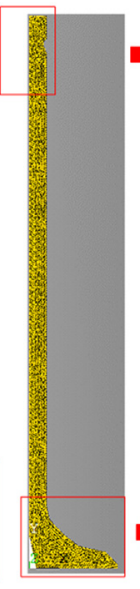

b)
Fig. 9. Mesh generation for (a) exhaust valve and (b) intake valve.

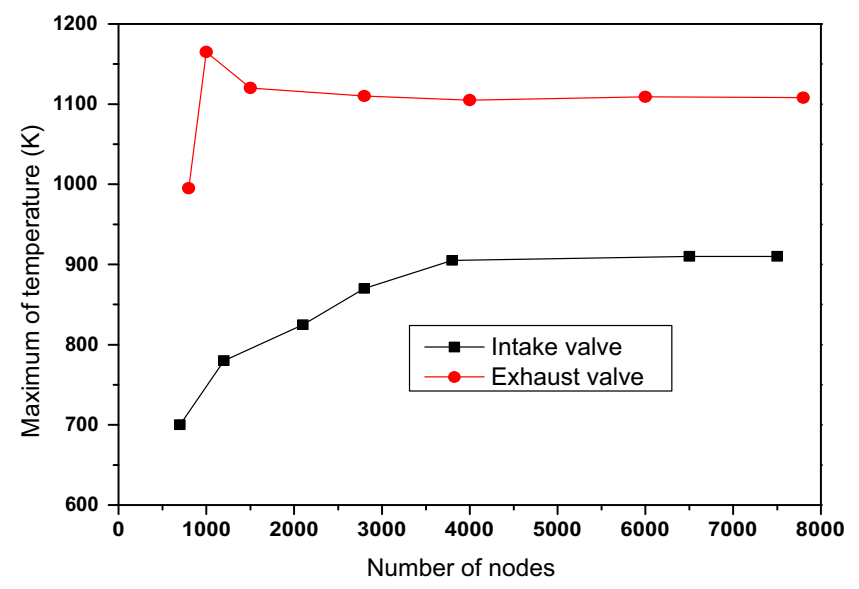

Fig. 10. Grid dependency.

3.2.6. HTC valve stem_tip. The cyclic motion of the valve takes place with the help of a rocker lever, which is connected to the push rod. The push rod rests over cams on the camshaft. The tip of the valve is exposed to air and by ignoring the friction between the stem tip and the cams system, a fixed value assigned of the heat transfer coefficient to this area could not be a very remoteness to the reality. Thus, the boundary condition in terms of adiabatic wall temperature and the heat transfer coefficient are represented respectively by the temperature and convection coefficient of the air. They are assumed constant during the one engine cycle with values equal:

3.2.7. HTC valve stem_guide/tip. This part of stem is initially (valve close) out of the guide and during the valve opening, a part of this zone enter gradually to the guide until its maximum length, which of course correspond to the maximum of lift. The same way as stem_guide/port zone is used to obtain the instantaneous heat transfer coefficient and adiabatic wall temperature.

$$
\begin{aligned}
H T C_{\text {stem_guide/tip }}= & \left(\frac{L_{v, \operatorname{Max}}-L_{v}}{L_{v, \operatorname{Max}}}\right) H T C_{\text {stem_tip }} \\
& +\left(\frac{L_{v}}{L_{v, \operatorname{Max}}}\right) H T C_{\text {stem_guide }}
\end{aligned}
$$

\section{Case of application}

\subsection{Engine}

The exhaust and intake valves are mounted on 0.61 gasoline ICE where the main characteristics are presented in Table 3. This engine is modelled via the 1D Ricardo Wave software in order to generate the instantaneous thermodynamic parameters such as the in-cylinder temperature, temperature of exhaust gases and intake air, velocity of burned gases at exhaust port, which are difficult to measure experimentally.

\subsection{Valves geometry}

The geometry of the exhaust and intake valves are shown in Fig. 6-a. The length of both valve seats is $2.1 \mathrm{~mm}$ and the stem diameter is $9.5 \mathrm{~mm}$. The stem length is $12.91 \mathrm{~mm}$. The exhaust valve opens at a crank angle of 88 and closes at 410 CA, whereas the intake valves open at crank angle of 308 and close at -75 CA with an overlap of 102 CA (see Fig. 6-b). The maximum lift is about $9.9 \mathrm{~mm}$.
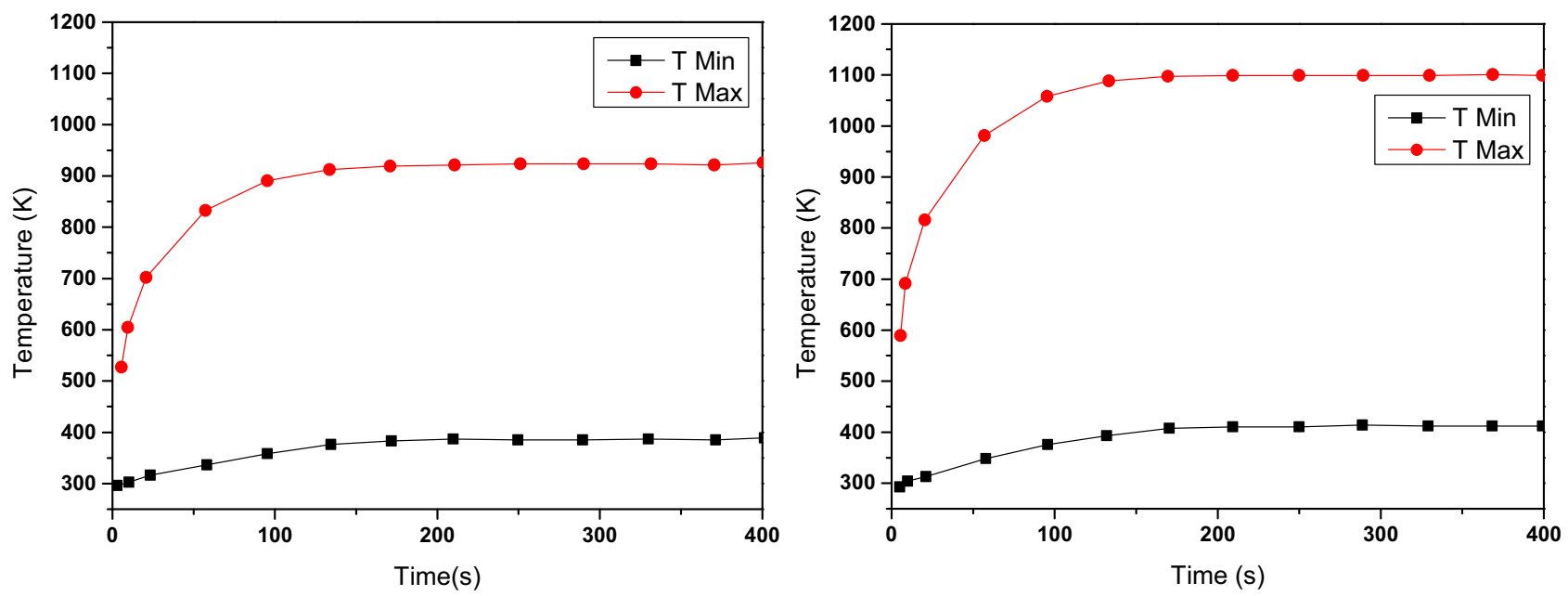

Fig. 11. Evolution of the maximum and minimum temperature of (a) intake valves and (b) exhaust valve. 

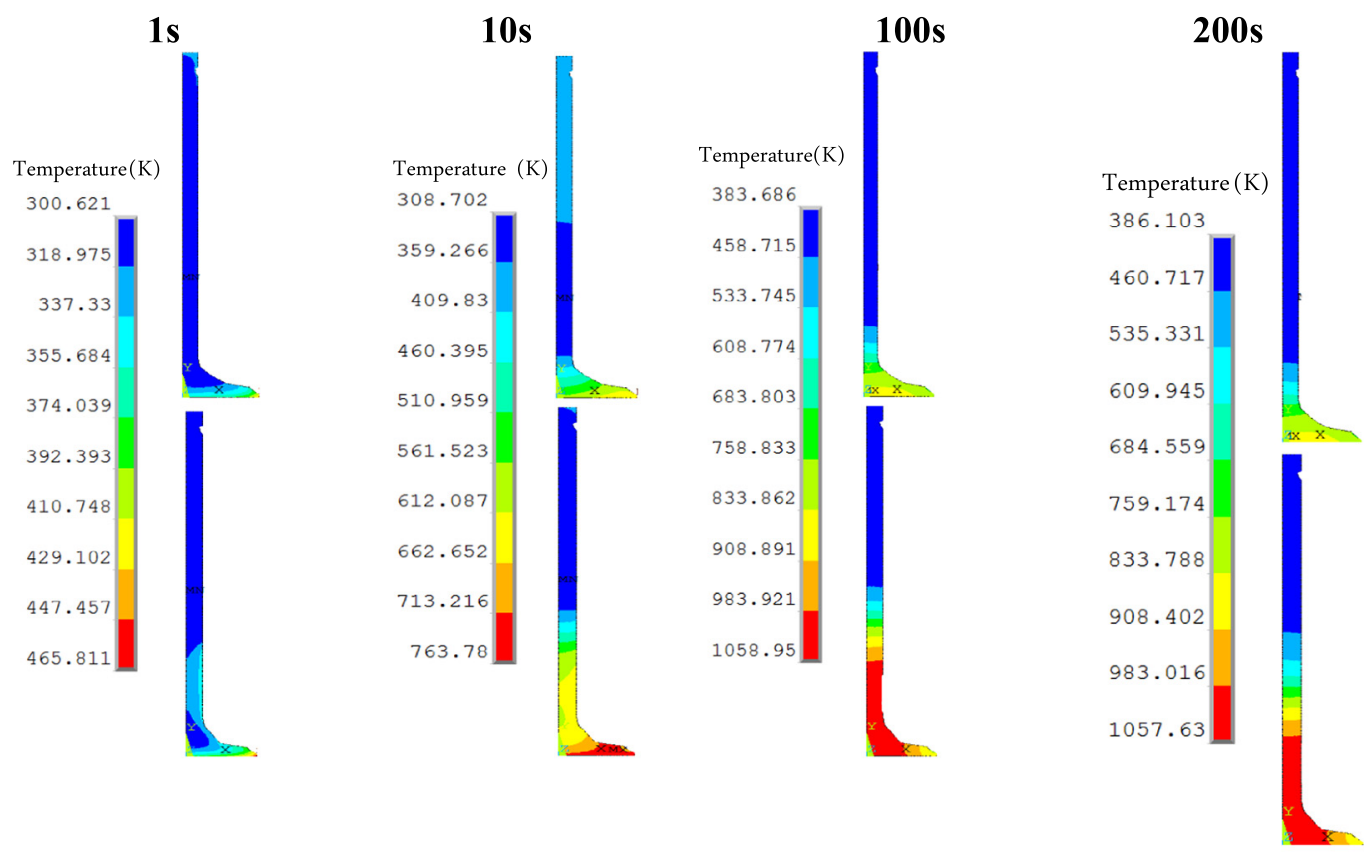

a) Temperature map for the intake valve (top) and the exhaust valve (buttom)
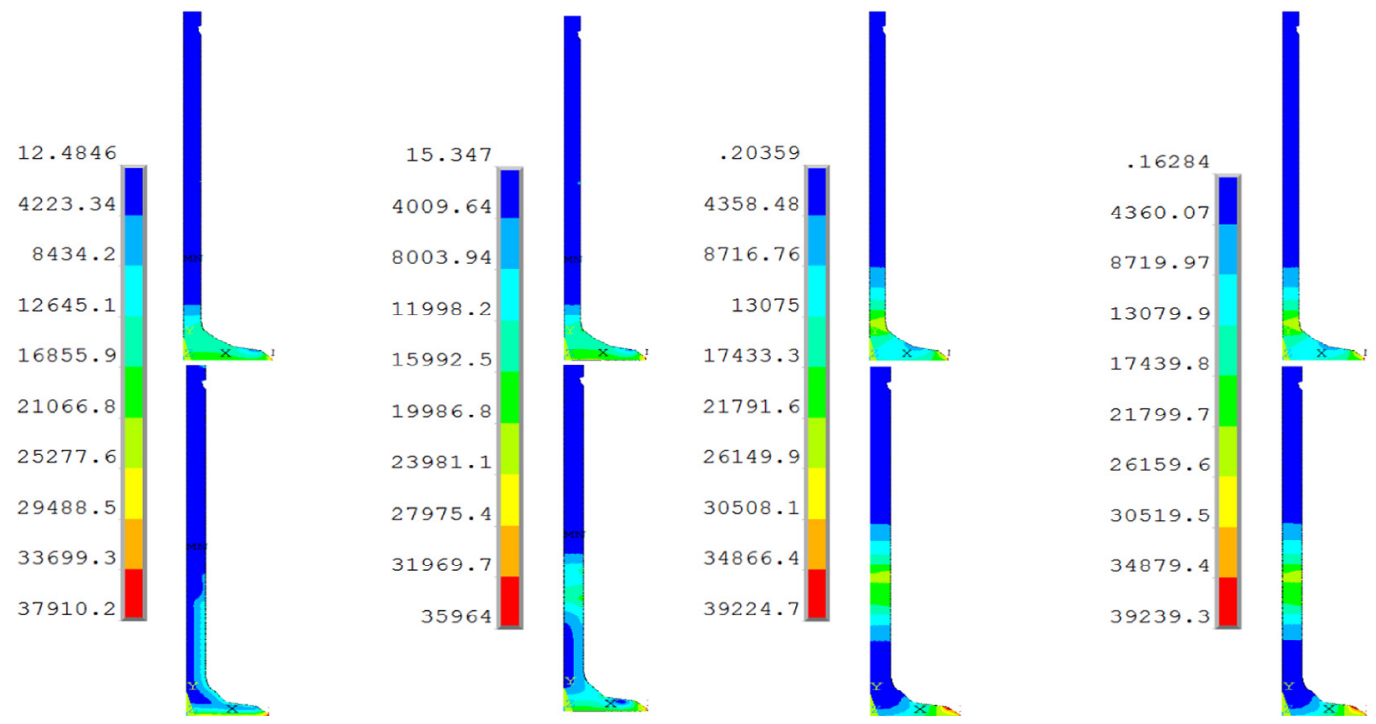

b) Thermal gradient for the intake valve (top) and the exhaust valve (buttom)

Fig. 12. Temperature map and thermal gradient for the exhaust and intake valves at different time at engine speed of 5500 .

\subsection{Boundary conditions for the exhaust and intake valves}

\subsubsection{An example of transient HTC and AWT}

Fig. 7 shows an example of the evolution of transient HTC and AWT over one engine cycle, for the case of the exhaust valves at an engine speed of $5500 \mathrm{rpm}$.

The transient HTC is obtained using Woschni correlation [17], it reaches a maximum of $2593 \mathrm{~W} / \mathrm{m}^{2} \mathrm{~K}$ that corresponds to the maximum of in-cylinder pressure. The adiabatic wall temperature is incylinder temperature of gases provide directly by the software Ricardo Wave (see Fig. 7-a).

At the zone seat (Fig. 7-b), the instantaneous exhaust gas temperature is taken as an AWT when the valve is open, and while the valve is close, the AWT is that of fluid cooling. The HTC is shown to rapidly increase with the combustion process due the rapid pressure rise whereas when the exhaust is closed the HTC drops to relatively low values. The effect of lift law is directly identified by the three zones as shown in Fig. 7-b. Fig. 7-c highlight the instantaneous exhaust gas temperature recorded at the port, which is considered as adiabatic wall temperature. During the opening of exhaust valve, the burned gases leave the cylinder with a high velocity, causing a rapid increase in HTC. For the remaining zones (Fig. 7, d-f)), the AWT and HTC are directly a combination of the average between the values of HTC an AWT in the guide and the parts which be included in the port or exit the guide.

\subsubsection{Average HTC at various engine speeds}

The transient boundary conditions, in term of HTC and AWT for both intake and exhausts valves, is obtained for all zones and at diverse engine speeds by varying the input parameters. Then, the 

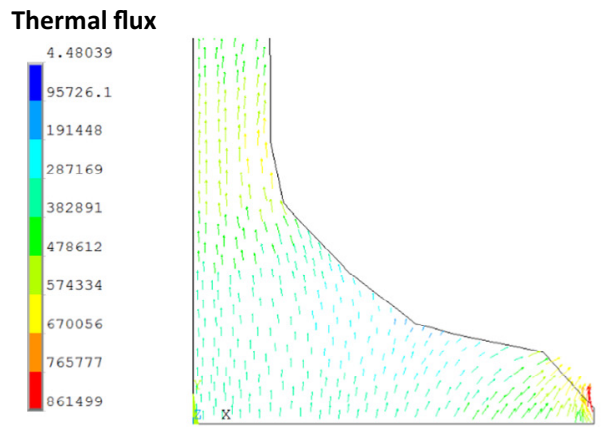

a)
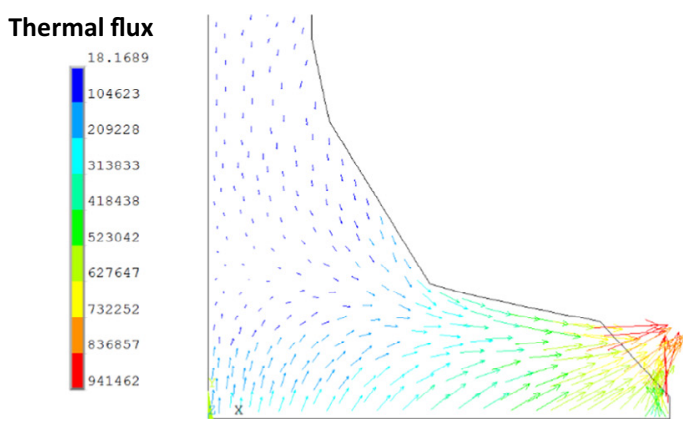

b)

Fig. 13. Thermal flux (a) intake valves (b) exhaust valve.

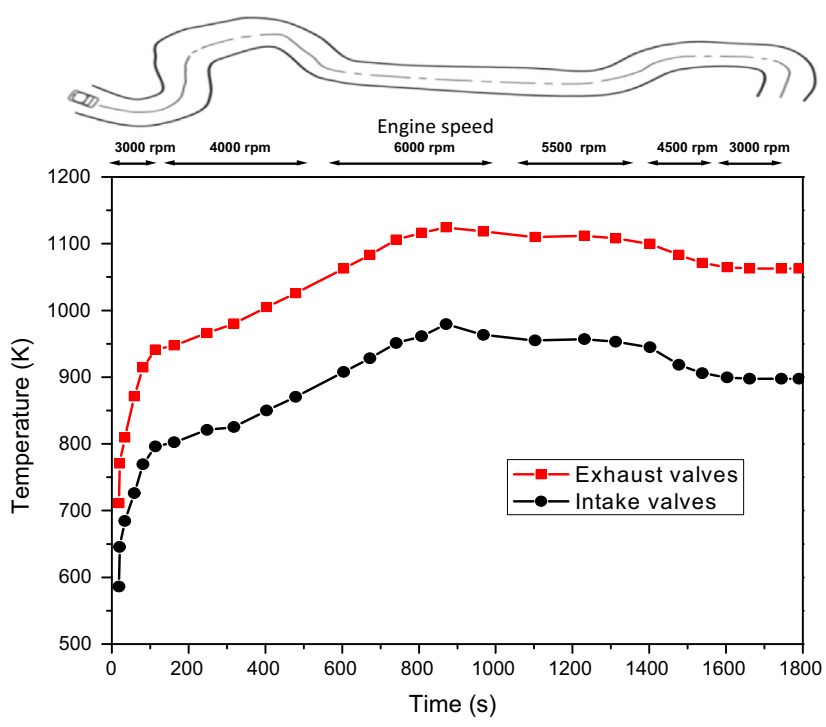

Fig. 14. Maximum Temperature evolution of an exhaust and intake valves after a furtive circuit.

average values of the boundary condition for each zone of both valves are elaborated during one cycle of the engine.

Fig. 8 presents the averaged HTC in function of engine speed for combustion face, seat, port zone and port/guide zone for both valves. The heat transfer coefficient for the combustion face is identical for the exhaust and intake valve since they are imposed to the same pressure and temperature of gases. Mainly, the heat transfer coefficients for all zones present linear trends at low engine speeds, whereas at high engine speed polynomial behaviours are showed mostly at seat zone. For stem zone, the heat transfer coefficient is almost linear for all the range of engine speed. Polynomial fittings are superimposed to the findings to well describe the trend of the heat transfer coefficient versus engine speed. Table 4 summarizes constant of the polynomial for each zones.

\subsection{Finite element analysis}

The 2D transient isotopic solid FEM model was developed to simulate the conduction through this valve, in which the temperature field is a function of time and spatial coordinates. The 2D fournode thermal plane element, PLANE55, was applied to mesh the whole of valve. Fig. 9 illustrates the meshed elements near tip and head for both valves. In order to limit the effect of number of nodes on the finale results, seven meshed were generated for both valves. The grid dependency is based on the fact that errors due to the spatial discretization should be minimized, as the grid is refined. Fig. 10 shows the maximum of temperature within the exhaust and intake valves stabilized at 4015 and 3811 nodes, respectively.

To facilitate simulation runs of the proposed model, an APDL was used. The thermal conductivity of valve material is equal to $28 \mathrm{~W} / \mathrm{m}^{2} \mathrm{~K}$ and the density is about $7780 \mathrm{~kg} / \mathrm{m}^{3}$.

\subsection{Heat transfer analyses within intake and exhaust valves}

\subsubsection{Maximum temperature}

The comparison between the heat transfer through the intake and exhaust valves is made in term of maximum temperature that valves reach and the required time to reach the stable regime is depicted in Fig. 11. For a rotational speed about $4500 \mathrm{rpm}$ of the engine, the maximum temperatures stabilize to attain $881 \mathrm{k}$ and $1127 \mathrm{~K}$ for the intake and exhaust valves, respectively. Moreover, a double time is required for the intake valve (about $200 \mathrm{~s}$ ) to reach it maximum compared to the exhaust valves (100 s).

\subsubsection{Temperature and thermal gradient}

Fig. 12 a-d b show the temperature map and thermal flux of both exhaust valve and intake valves at an engine speed of $5500 \mathrm{rpm}$ four times $1 \mathrm{~s}, 10 \mathrm{~s}, 100 \mathrm{~s}$ and $200 \mathrm{~s}$. The maximum value of temperature is recorded through the overall valves typically at the combustion face since it is directly exposed to the in-cylinder temperature. At the steady state, the maximum temperature of the exhaust valve is higher about $177 \mathrm{~K}$ than the intake valve even if they are very close spatially, thus, indicating the arduous thermal condition affecting the exhaust valves.

For the exhaust valves, it is clearly apparent that the zone labelled stem-guide/port records a rapid drop in term of temperature; therefore, with the cyclic motion of the valve, this area is susceptible to a high thermal fatigue and it can be indicated as critical zone. However, for the intake valve, we note a gradually decrease of the temperature from the head to the tip. This behaviour is consolidating by the field of the thermal gradient, which shows a clear slope in the exhaust valves mainly in the stem_port/guide and the seat zones.

\subsubsection{Thermal flux}

Fig. 13 depicts the propagation of heat flux density near valves heads at the steady state condition. When comparing the flux density within the intake and exhaust valves, we not that the vectors of heat flux density are mainly directed to the seat zone for the intake valves to continuously remove the heat from valve head due to high difference between the regions of seat and engine 
block. For both valves, the values recorded in term of thermal flux valve are good indicator of the zone of high thermal stresses. They will help prediction of the optimum working temperature and thus the adequate material properties.

\subsubsection{Maximum of valves temperature at various engine speeds}

The findings of the present approach allow also predicting details about the maximum temperature of exhaust valves after series of engine regimes. Fig. 14 presents the evolution of maximum temperature of an exhaust valves after a furtive circuit. Such results have their importance when focusing in the real thermal loading of overall or a part of exhaust valves, it gives a good prediction of the both temperature map for actual the actual operating condition, which certainly help to avoid any extreme thermal load.

\section{Conclusion}

A simple numerical model performed in the present work for assessing the temperature map of an exhaust and an intake valves, based upon the basic concept of the heat transfer and available correlation related to internal combustion engine. The valve is, firstly, subdivided to several zones in the aim to better assess the effect of each part of the cylinder head, thus, to identify the instantaneous boundary conditions for each part. A comparison between the exhaust and intake valves in term of heat transfer coefficient at each zones, maximum temperature and temperature map allows identifying thermal loading of each valves. The HTC are shown to vary linearly at low engine speed and takes polynomial trend at high engine speed. In addition, the intake valves are shown to take double time compared to the exhaust valves to stabilize. The present approach allows quantifying the temperature distribution, thermal gradient and thermal flux of each zone constituting the valves and at various engine speed, which help metallurgist to rise the lifetime of valves.

\section{References}

[1] J. Heywood, Internal combustion engine fundamentals, McGraw-Hill International Editions, 1988.

[2] A.H. Gibson, H. Wright Baker, Exhaust-Valve and Cylinder-Head Temperatures in High-Speed Petrol Engines, in: Proceedings of the Institution of Mechanical Engineer, 1923, https://doi.org/10.1243/PIME_PROC_1923_105_0 25_02.

[3] M.A. Zipkin, J.C. Sander, Correlation of exhaust valve temperature with engine operating condition and valve design in an air cooled cylinder, NASA report no 813, 1945.

[4] A. Pandey, R.K. Mandloi, Effects of high temperature on the microstructure of automotive engine valves, Int. J. Eng. Res. Appl. 4 (3 (Version 1)) (2014) 122126.

[5] E.S. Dennison, T.C. Kuchler, D.W. Smith, Experiments on flow of air through engine valves, Trans. Am. SOC. Mech. Engrs. 53 (17) (1931) 79.

[6] B.S. Han, Y.J. Chung, Y.J. Kwon, S. Lee, Empirical formula for instantaneous heat transfer coefficient in spark ignition engines, SAE Paper 972995 (1997).

[7] W.A. Woods, S.R. Rhan, An experimental study of flow through poppet valves, in: Proceedings of the Institution of Mechanical Engineers Conference Proceeding, $1965, \quad$ p. $\quad 32, \quad$ https://doi.org/10.1243/ PIME_CONF_1965_180_383_02.

[8] Bjoern Franzke, Stefan Pischinger, Philipp Adomeit, Christof Schernus, Johannes Scharf, Tolga Uhlmann, A sectoral approach to modelling wall heat transfer in exhaust ports and manifolds for turbocharged gasoline engines, SAE
Int. J. Mater. Manf. 9 (2) (2016) 276-285, https://doi.org/10.4271/2016-010202.

[9] L.V. Plotnikov, B.P. Zhilkin, The gas-dynamic unsteadiness effects on heat transfer in the intake and exhaust systems of piston internal combustion engines, Int. J. Heat Mass Transf. 115 (2017) 1182-1191.

[10] Liejin Guo, Xuejun Chen, Ziping Feng, Bofeng Bai, Transient convective heat transfer in a helical coiled tube with pulsatile fully developed turbulent flow, Int. J. Heat Mass Transf. 41 (19) (1998) 2867-2875, https://doi.org/10.1016/ S0017-9310(98)80003-3.

[11] Incropera, F. P. and DeWitt, D. P., "Fundamentals of Heat and Mass Transfer", 6th ed.; 2007.

[12] Mavropoulos, G.C., Rakopoulos, C.D. „Hountalas, D.T. Experimental investigation of instantaneous cyclic heat transfer in the combustion chamber and exhaust manifold, SAE paper, 2009-01-1122.

[13] G.C. Mavropoulos, Experimental study of the interactions between long and short-term unsteady heat transfer responses on the in-cylinder and exhaust manifold diesel engine surfaces, Appl. Energy 88 (3) (2011) 867-881.

[14] G.R. Tomlinson, R. Leonard, S.H. Henshall, Research note: a method for assessing the maximum temperature of exhaust valves in internal combustion engines, J. Mech. Eng. Sci. 16 (4) (1974) 279-280.

[15] M.H. Shojaefard, A.R. Noorpoor, D.A. Bozchaloe, M. Ghaffarpour, Transient thermal analysis of engine exhaust valve, Numer. Heat Transf., Part A 48 (2005) 627-644, https://doi.org/10.1080/10407780590959943.

[16] M.I. Karamangil, A. Avci, H. Bila, Investigation of the effect of different carbon film thickness on the exhaust valve, Heat Mass Transf. 44 (2008) 587-598, https://doi.org/10.1007/s00231-007-0271-6.

[17] Lucjan Witek, Failure and thermo-mechanical stress analysis of the exhaust valve of diesel engine, Eng. Fail. Anal. 66 (2016) 154-165, https://doi.org/ 10.1016/j.engfailanal.2016.04.022.

[18] M. SaeidBaniasad, Emad Khalil and Feng Shen "Exhaust Valve Thermal Management and RobustDesign Using Combustion and 3D ConjugateHeat Transfer Simulation with6-Sigma Methodology " SAE paper 2006-01-0889.

[19] Gregory Roth; "Fatigue Analysis Methodology for Predicting Engine Valve Life"; SAE paper 2003-01-0726.

[20] M. Cerdoun, C. Carcasci, A. Ghenaiet, An approach for the thermal analysis of internal combustion engines' exhaust valves, Appl. Therm. Eng. (2016), https:// doi.org/10.1016/j.applthermaleng.2016.03.105.

[21] M. Cerdoun, C. Carcasci, A. Ghenaiet, Analyses of unsteady heat transfer of internal combustion engines exhaust valves, J. Engine Res. (2018).

[22] Alpaya, Mert, Iskender Kayabasi, Burag Hamparyan, Orcun Aslan“ Transient thermal modeling of a four-stroke internal combustion engine exhaust valve." ASTFE Digital Library. Begel House Inc., 2019.

[23] W.J.D. Annand, Heat transfer in the cylinders of reciprocating internal combustion engines, Proc. Instn. Mech. Engrs. 177 (36) (1963) 973-990.

[24] Woschni ,G. 'Electronic calculation of the time curve of pressure, temperature and mass flow rate in the cylinder of a diesel engine', Computers in internal combustion engine design, Proc. Instn mech. Engrs 1967-68 182 (Ft 3L).

[25] L.J. Kastner, T.J. Williams, J.B. White, Poppet inlet valve characteristics and their influence on the induction process, Proc. Instn. Mech. Engrs 178 (1) (1963) 951-978.

[26] Dittus, P.W., Boelter, L. M., University of California, Berkeley, Publications on Engineering, 1930, 2, pp 44.

[27] S.W. Churchill, M. Bernstein, A correlating equation for forced convection from gases and liquids to a circular cylinder in crossflow, J. Heat Trans.: T ASME 99 (1977) 300-306

[28] B.B. Mikic, Thermal contact conductance theoretical considerations, Int. J. Heat Mass Tran. 17 (2) (1974) 205-214.

[29] M. Cooper, B. Mikic, M. Yovanovich, Thermal contact conductance, Int. J. Heat Mass Tran. 12 (1969) 1517-1520.

[30] M. Sridhar, M. Yovanovich, Elastoplastic contact conductance model for isotropic conforming rough surfaces and comparison with experiments, J. Heat Trans: T 118 (1) (1996) 3-9.

[31] Carlos Carcasci, Bruno Facchini, A numerical procedure to design internal cooling of gas turbine stator blades, Revue Générale de Thermique 35 (412) (1996) 257-268, https://doi.org/10.1016/S0035-3159(96)80018-3.

[32] Czeslaw O. Popiel (2008) Free Convection Heat Transfer from Vertical Slender Cylinders: A Review, Heat Transfer Engineering, 29:6, and 521-536, DOI: $10.1080 / 01457630801891557$.

[33] C.V. Madhusudan, Thermal conductance of cylindrical joints, Int. J. Heat Mass Tran. 42 (1999) 1273-1287. 